International Journal of Research in Engineering and Innovation
(IJREI)
jJREurnal home page: http://www.ijrei.com

\title{
Energy \& Exergy analysis (Thermodynamic analysis) of a multi-evaporators vapour compression refrigeration system using ecofriendly refrigerants (R410a, R290, R600, R600a, R1234yf, R502, R404a and R152a)
}

\author{
R.S. Mishra ${ }^{1}$, Kapil Chopra ${ }^{2}$ \\ ${ }^{I}$ Department of Mechanical, Production, Industrial and Automobiles Engineering, Delhi technological University, Delhi, India \\ ${ }^{2}$ Department, Mechanical Engineering, MVDVV, Katra, India.
}

\begin{abstract}
In this paper detailed energy and exergy analysis of multi-evaporators at the same temperature with single compressor and expansion valve vapour compression refrigeration system has been done in terms of performance parameter for R410a, R290, R600, R600a, $\mathrm{R} 1234 \mathrm{yf}, \mathrm{R} 502, \mathrm{R} 404 \mathrm{a}$ and R152a refrigerants. It was observed that first law and second law efficiency improved by $22.5 \%$.Exergetic defect in expansion valve is highest at constant condenser temperature and exergetic defect in condenser is highest by keeping constant evaporator temperature .It was also observed that performance of above systems using R600 and R152a nearly matching same values under the accuracy of 5\% can be used in the above system .But difficulties using R600, R290 and R600a is flammable problems therefore safety measures are required using these refrigerants, therefore R152a refrigerant is recommended.

Keywords: COP, Irreversibility, Exergetic efficiency, Relative COP, Efficiency defect

(c) 2019 ijrei.com. All rights reserved
\end{abstract}

\section{Introduction}

This paper deals with a comparative investigation of the refrigerant impact on the performances of a multi-evaporators vapor compression refrigeration system. The purpose of this paper is to present and propose an analysis model for comparing the performances of multi-evaporators VCR System with considered refrigerants.

It is well known the fact that after 90's CFC and HCFC refrigerants have been prohibited due to presence of chlorine content and their high ozone depleting potential and global warming potential. Thus, HFC refrigerants are used nowadays, showing much lower global warming potential value, but still high with respect to non-fluorine refrigerants.

Many research papers have been published on this subject, of replacing "old" refrigerants with "new" ones [1-6]. Lately, many papers focused on researches about searching better and better refrigerants or mixtures, considering different criteria, as for example: COP, EDR, exergetic efficiency, and exergy defect in compressor, condenser, expansion valve sub-cooler and evaporators.

This paper presents a comparative analysis of eight refrigerants working in a multi-evaporators VCR system with subcooling and superheating.

These eight refrigerants are:1,2-Difluoroethane (R152a), Propane (R290), Butane (R600),Isobutane (R600a),2,3,3,3- Tetra-fluoropropene (R1234yf), a azeotropic blend (R404a), (R410a) and (R502). R404a is a near-azeotropic blend of R125 / R143a / $\mathrm{R} 134 \mathrm{a}$ with mass percentages of $44 \%$ / 52\% / 4\%.R410a is an azeotropic blend of Difluoromethane R32 Pentafluoro-ethane R125 with mass percentages of 50\% / 50\%. Blends do not necessarily remain at constant temperature during constant pressure evaporation or condensation.

\section{Energy and exergy analysis}

The multiple evaporators at the same temperature with single compressor and expansion valve vapour compression refrigerator with subcooler is shown in Fig. 1. 


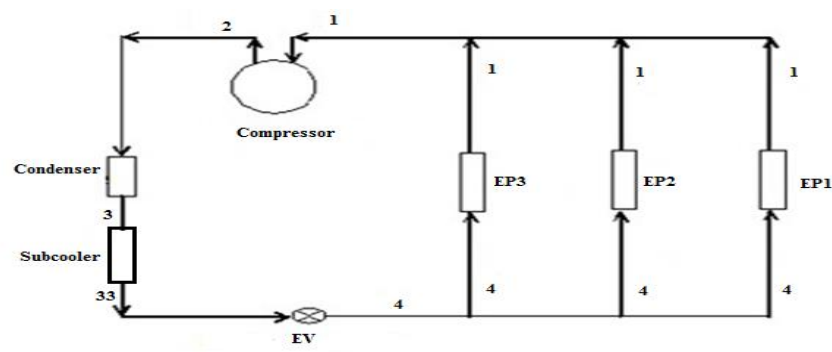

Figure 1: Schematic diagram of a multi-evaporators vapour compression refrigeration system.

According to first law of thermodynamics, the measure of performance of the refrigeration cycle is the coefficient of performance (COP), which is defined as the net refrigeration effect produced per unit of work input. It is given as

$$
\mathrm{COP}=\frac{Q_{e}}{W_{\text {Comp }}}
$$

The concept of exergy was given by second law of thermodynamics, which always decreases due to thermodynamic irreversibility. Exergy is defined as the measure of usefulness, quality or potential of a stream to cause change and an effective measure of the potential of a substance to impact the environment [7]. Exergy balance for a control volume undergoing steady state process is expressed as [8].

Where IRk indicates the rate of irreversibility occurring in Compressor, Expansion valve, Evaporators, Condenser, and Subcooler. The first two terms on the right hand side represent exergy of streams entering and leaving the control volume. The third and fourth terms are the exergy associated with heat transfer $\mathrm{Q}$ from the source maintained at constant temperature $\mathrm{T}$ and is equal to work obtained by Carnot engine operating between $\mathrm{T}$ and To, and is therefore equal to maximum reversible work that can be obtained from heat energy Q. The last term is the mechanical work transfer to or from the control volume.

\subsection{Irreversibility $(I R)$ in the system components}

Irreversibility in each component of the cycle is calculated as per Eqs. (3)- (9) Specified below: Evaporator-1

$$
\begin{gathered}
I R_{k}=\sum\left(m e_{x}\right)_{\text {in }}-\sum\left(m e_{x}\right)_{\text {out }}+\left[\sum\left(Q\left(1-\frac{T_{0}}{T}\right)\right)_{\text {in }}-\sum\left(Q\left(1-\frac{T_{0}}{T}\right)\right)_{\text {out }}\right] \pm \sum W \\
I R_{e 1}=E_{x 4}+Q_{e 1}\left(1-\frac{T_{0}}{T_{r}}\right)-E_{x 1}=m_{r 1}\left(h_{4}-T_{0} s_{4}\right)+Q_{e 1}\left(1-\frac{T_{0}}{T_{r}}\right)-m_{r 1}\left(h_{1}-T_{0} s_{1}\right) \\
\text { Evaporator- } 2
\end{gathered}
$$

$$
I R_{e 2}=E_{x 4}+Q_{e 2}\left(1-\frac{T_{0}}{T_{r}}\right)-E_{x 1}=m_{r 2}\left(h_{4}-T_{0} s_{4}\right)+Q_{e 2}\left(1-\frac{T_{0}}{T_{r}}\right)-m_{r 2}\left(h_{1}-T_{0} s_{1}\right)
$$

Evaporator-3

$$
I R_{e 3}=E_{x 4}+Q_{e 3}\left(1-\frac{T_{0}}{T_{r}}\right)-E_{x 1}=m_{r 3}\left(h_{4}-T_{0} s_{4}\right)+Q_{e 3}\left(1-\frac{T_{0}}{T_{r}}\right)-m_{r 3}\left(h_{1}-T_{0} s_{1}\right)
$$

Compressor

$$
\mathrm{IR}_{\text {comp }}=\mathrm{E}_{\mathrm{x} 1}+\mathrm{W}_{\text {comp }}-\mathrm{E}_{\mathrm{x} 2}=\mathrm{m}_{\mathrm{r}}\left(\mathrm{T}_{\mathrm{o}}\left(\mathrm{s}_{2}-\mathrm{s}_{1}\right)\right)
$$

Condenser

$$
\mathrm{IR}_{\mathrm{c}}=\mathrm{E}_{\mathrm{x} 2}-\mathrm{E}_{\mathrm{x} 3}=\mathrm{m}_{\mathrm{r}}\left(\mathrm{h}_{2}-\mathrm{T}_{\mathrm{o}} \mathrm{s}_{2}\right)-\mathrm{m}_{\mathrm{r}}\left(\mathrm{h}_{3}-\mathrm{T}_{\mathrm{o}} \mathrm{s}_{3}\right)
$$

Expansion Valve

$$
\mathrm{IR}_{\mathrm{ev}}=\mathrm{E}_{\mathrm{x} 33}-\mathrm{E}_{\mathrm{x} 4}=\mathrm{m}_{\mathrm{r}}\left(\mathrm{T}_{\mathrm{o}}\left(\mathrm{s}_{4}-\mathrm{S}_{33}\right)\right)
$$

Subcooler

$$
\begin{aligned}
& \mathrm{IR}_{\mathrm{sc}}=\mathrm{E}_{\mathrm{x} 3}-\mathrm{E}_{\mathrm{x} 33}=\mathrm{m}_{\mathrm{r}}\left(\mathrm{h}_{3}-\mathrm{T}_{\mathrm{o}} \mathrm{s}_{3}\right)-\mathrm{m}_{\mathrm{r}}\left(\mathrm{h}_{33}-\mathrm{T}_{\mathrm{o}} \mathrm{s}_{33}\right) \\
& \sum I R_{k}=I R_{e 1}+I R_{e 2}+I R_{e 3}+I R_{c o m p}+I R_{c}+I R_{e v}+I R_{s c}
\end{aligned}
$$




\subsection{Total irreversibility}

The total irreversibility in the system is the sum of irreversibility in each components of the system and is given by eq. 11 .

\subsection{Thermal exergy loss}

Thermal exergy loss rate in a component is given by

$E L_{k}=Q_{k}\left(1-\frac{T_{0}}{T_{k}}\right)$

Where $\mathrm{Q}_{\mathrm{k}}$ is the heat rejected by the $\mathrm{k}_{\mathrm{th}}$ component and $\mathrm{T}_{\mathrm{k}}$ is the temperature at the boundary of the $\mathrm{k}_{\mathrm{th}}$ component. When considering thermal exergy loss rate, Eq. (2) can be rewritten as

$I R_{k}+E L_{k}=\sum\left(m e_{x}\right)_{\text {in }}-\sum\left(m e_{x}\right)_{\text {out }}+\left[\sum\left(Q\left(1-\frac{T_{0}}{T}\right)\right)_{\text {in }}\right] \pm$ $\sum W$

Thermal exergy loss rate is related to external irreversibility which takes place because of temperature difference between the control volume and the external environment. It depends upon how the boundary of the system is chosen. If the system includes the external surrounding then the boundary of the thermal system is at the same temperature as the temperature of immediate surroundings and hence the value of thermal exergy loss becomes zero. However, temperature differential between system boundary and external surroundings exists if the system boundary does not include the immediate surroundings. In a vapour compression refrigeration system, heat is rejected by the condenser. However in this case, thermal exergy loss in condenser is ignored as the boundary of the condenser is supposed to be at the surrounding temperature. Second law performance of the system can be measured in terms of exergetic efficiency [9]. Exergetic efficiency is the ratio between exergy rate of product and input energy. If we consider a system at steady state where, in terms of exergy, the rates at which the fuel is supplied and the product is generated are EF and EP, respectively, and $\sum I R_{\mathrm{k}}$ and $\sum E L_{\mathrm{k}}$ represent rate of total irreversibility and total thermal exergy loss in a present system, respectively, then exergy rate balance for the system is given by (13) and second law efficiency by (14).

$E F=E P+\sum I R_{k}+\sum E L_{k}$

\subsection{Second law efficiency (Exergetic efficiency)}

For the multi evaporators vapour compression refrigeration system, product is the exergy of the heat abstracted in to the evaporators i.e. $Q_{e}=Q_{e 1}+Q_{e 2}+Q_{e 3}$ from the space to be cooled at temperature $\mathrm{T}_{\mathrm{r}}$, i.e.

$\eta_{\text {ex }}=\frac{\text { Exergy in product }}{\text { Exergy of fuel }}=\frac{E P}{E F}=1-\frac{\sum I R_{k}+\sum E L_{k}}{E F}$
$E P=Q_{e}\left|\left(1-\frac{T_{0}}{T_{r}}\right)\right|$

and exergy of fuel is actual compressor work input, $\mathrm{W}_{\mathrm{c}}$. Hence, exergetic efficiency is given by

$\eta_{e x}=\frac{Q_{e}\left|\left(1-\frac{T_{0}}{T_{r}}\right)\right|}{W_{\text {comp }}}$

\subsection{Exergy destruction ratio (EDR)}

EDR is the ratio of total exergy destruction in the system to exergy in the product [10] and it is given by Eq.(17). EDR is related to the exergetic efficiency by Eq. (18)

$E D R=\frac{I R_{\text {total }}}{E P}=\frac{1}{\eta_{e x}}-1$

Therefore second law efficiency in terms of exergetic efficiency is expressed by following expression

$\eta_{\text {ex }}=\frac{1}{1+E D R}$

\subsection{Efficiency defect}

Efficiency defect is defined as the ratio between the exergy flow destroyed in each component and the exergy flow required to sustain the process [11] (i.e. the electrical power supplied to the compressor in the present case) and is given by

$\delta_{k}=\frac{\sum I R_{k}+\sum E L_{k}}{W_{\text {comp }}}$

Where $\mathrm{k}$ stands for particular component. The efficiency defects of the components are linked to the exergetic efficiency of the whole plant by means of the following relation:

$\eta_{e x}=\left(1-\sum_{k} \delta_{k}\right)$

\section{Results and Discussion}

A numerical model is developed for carrying out the energy and exergy analysis of the multi evaporators vapour compression refrigeration system for enhancing thermal performances using EES software [12].The performance parameters are calculated by assuming following specifications of the system shown in Figs.222 are given below:

1. Degree of sub cooling of liquid refrigerant in subcooler $\left(\Delta \mathrm{T}_{\mathrm{sc}}\right): 5 \mathrm{~K}$.

2. Adiabatic efficiency of compressor ( $\left.\eta_{\text {comp }}\right): 75 \%$.

3. Difference between evaporator and space temperature $\left(\mathrm{T}_{\mathrm{r}^{-}}\right.$ $\left.\mathrm{T}_{\mathrm{e}}\right): 5 \mathrm{~K}$.

4. Variation of evaporators' temperature $\left(\mathrm{T}_{\mathrm{e}}\right): 223 \mathrm{~K}$ to $273 \mathrm{~K}$.

5. Condenser temperature $\left(\mathrm{T}_{\mathrm{c}}\right): 313 \mathrm{~K}$ 
6. Dead state temperature $\left(\mathrm{T}_{0}\right): 298 \mathrm{~K}$

7. Dead state enthalpy $\left(\mathrm{h}_{0}\right)$ and entropy $\left(\mathrm{s}_{0}\right)$ of the refrigerants have been calculated corresponding to the dead state temperature $\left(\mathrm{T}_{0}\right)$ of $298 \mathrm{~K}$.

8. Loads on the evaporators EP1, EP2 and EP3 are $35 \mathrm{KW}$, $70 \mathrm{KW}$ and $105 \mathrm{KW}$ respectively.

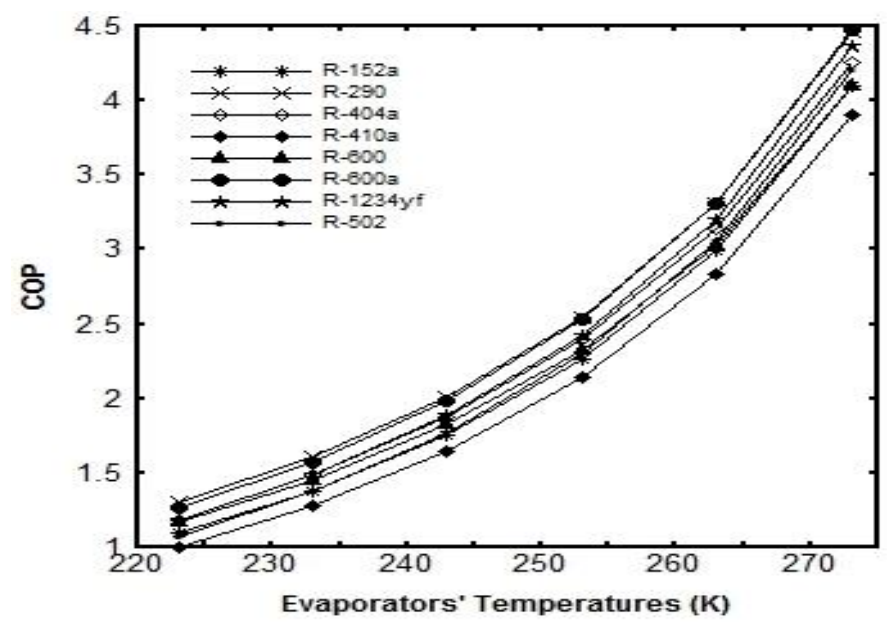

Figure 1: Variation of COP with evaporators' temperatures

Fig. 2 presents the variation of coefficient of performance against evaporators' temperature at $313 \mathrm{~K}$ condenser temperature. With increase in evaporators' temperature, the pressure ratio across the compressor reduces causing compressor work to reduce and cooling capacity increases because of increase in specific refrigerating effect. The combined effect of these two factors is to increase the overall COP. It was observed that COP of system using R600 and R152a nearly matching same values Both R-600 and R-152a show better COP than R-502, R-290, R-404a, R410a, R-600a and R-1234yf at $313 \mathrm{~K}$ condenser temperature. Although R600,R600a and R290 have flammable properties cannot use directly due to safety measures, the system will be modified by taking into the considerations safety measures and precautions must be taken when using these refrigerants and also they are responsible for global warming. The maximum difference observed between COPs of R-152a and R-404a is $22.57 \%$ at $313 \mathrm{~K}$ condenser temperature.

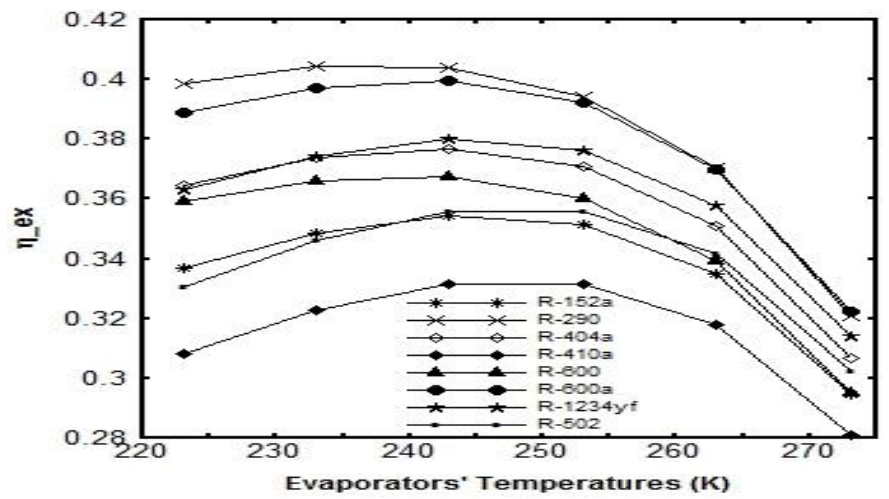

Figure 3: Variation of exergetic efficiency $\left(\eta_{e x}\right)$ with evaporators' temperatures

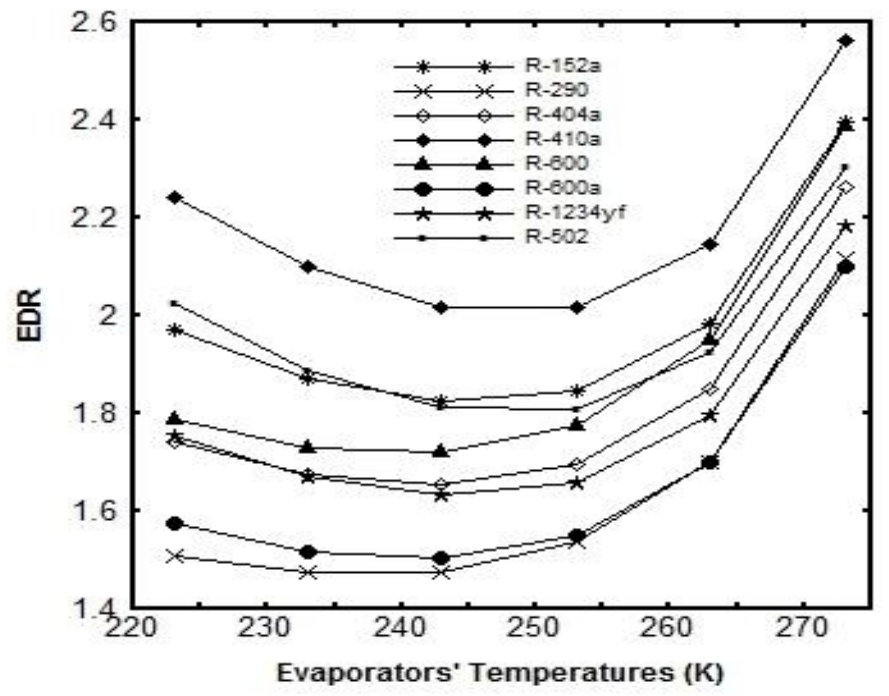

Figure 4: Variation of EDR with evaporators' temperatures

Fig. 3 shows the effect of evaporators' temperature on exergetic efficiency at $313 \mathrm{~K}$ condenser temperature. As clear from the Eq. (16) that the increase and decrease of the second law efficiency, with increase in evaporators temperature, are based on two parameters. First parameter is exergy of cooling effect, i.e., $Q_{e} \mid 1$ $\mathrm{T}_{\mathrm{o}} / \mathrm{T}_{\mathrm{r}}$ with rise in evaporators temperature $\mathrm{Q}_{\mathrm{e}}$, increases however the term $Q_{\mathrm{e}}\left|1-\mathrm{T}_{\mathrm{o}} / \mathrm{T}_{\mathrm{r}}\right|$ reduces since $\mathrm{T}_{\mathrm{r}}$ approaches $\mathrm{T}_{0}$, and second being the compressor work which decreases with increase in evaporators temperature. Both $\mathrm{Q}_{\mathrm{e}}$ and $\mathrm{W}_{\mathrm{c}}$ have positive effect on increase of second law efficiency whereas the decreasing value of term $\left|1-T_{0} / T_{r}\right|$ has a negative effect on increase of exergetic efficiency. The combined effect of these factors is to increase the second law efficiency till the optimum evaporators' temperature is reached, i.e. the evaporators' temperature at which maximum second law efficiency is achieved. After optimum evaporators' temperature, the combined effect of these factors is to decrease the second law efficiency. Both R600 and R152a have higher second law efficiency than R502, R290, R404a, R410a, R600a and R1234yf. Exergetic efficiency of R152a is 15-22\% higher than R404A and R600 is $12-20 \%$ higher than R404aA at $313 \mathrm{~K}$ condenser temperature. This also confirms that with increase in condenser temperature the difference among the second law efficiency of R152a, R600 and its alternate refrigerants increases.It is observed from Fig.3 and Fig.4 that variation of EDR and exergetic efficiency are almost reverse. This fact is also cleared from Eq. (15) that exergetic efficiency is inversely proportional to EDR. The EDR initially decreases and then increases with the increase in evaporators' temperature.The efficiency defects in the compressor, condenser, expansion valve, subcooler and evaporators are shown in Figs. 5-9. 


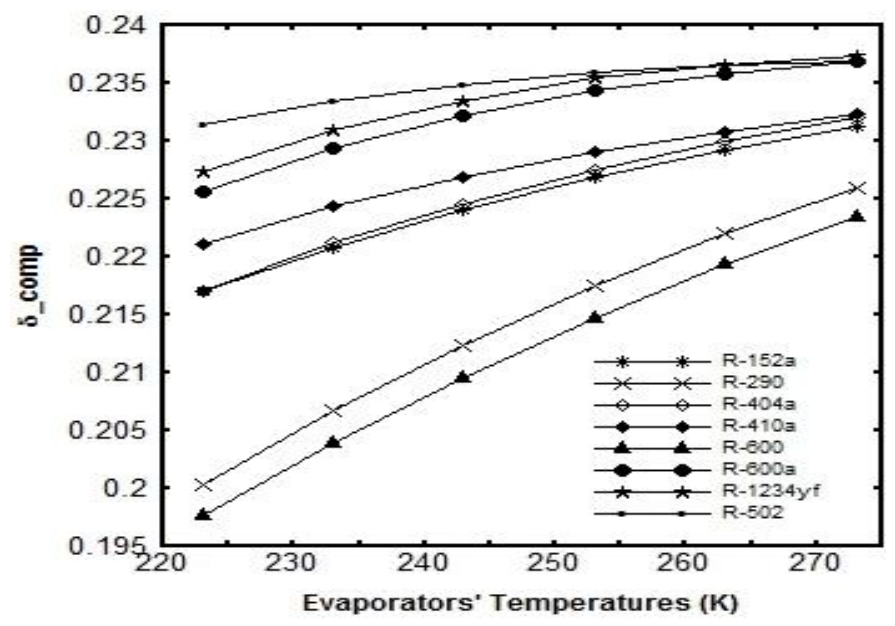

Figure 5: Comparison of efficiency defect in compressor $\left(\delta_{\text {comp }}\right)$ with evaporators' temperatures

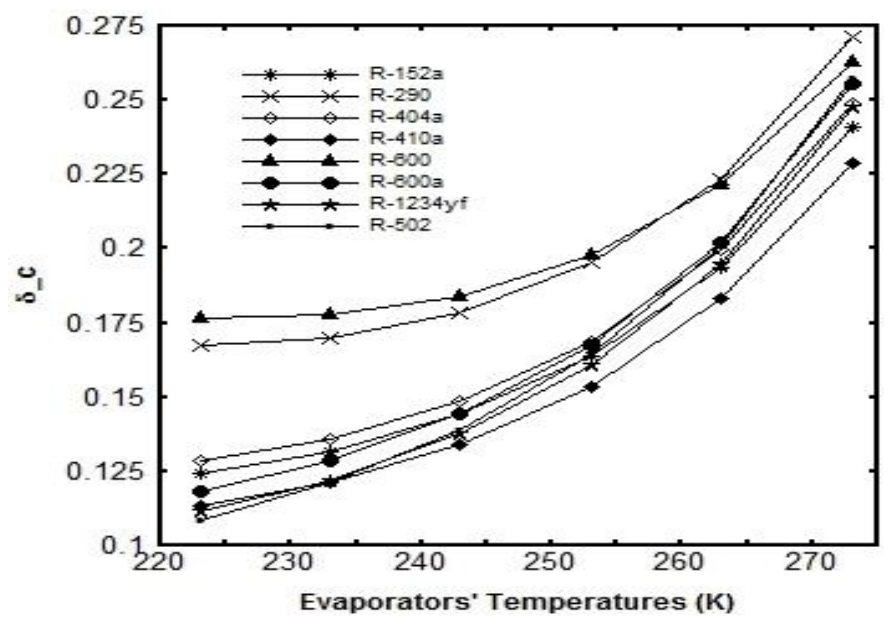

Figure 6: Comparison of efficiency defect in condenser $\left(\delta_{c}\right)$ with evaporators' temperatures

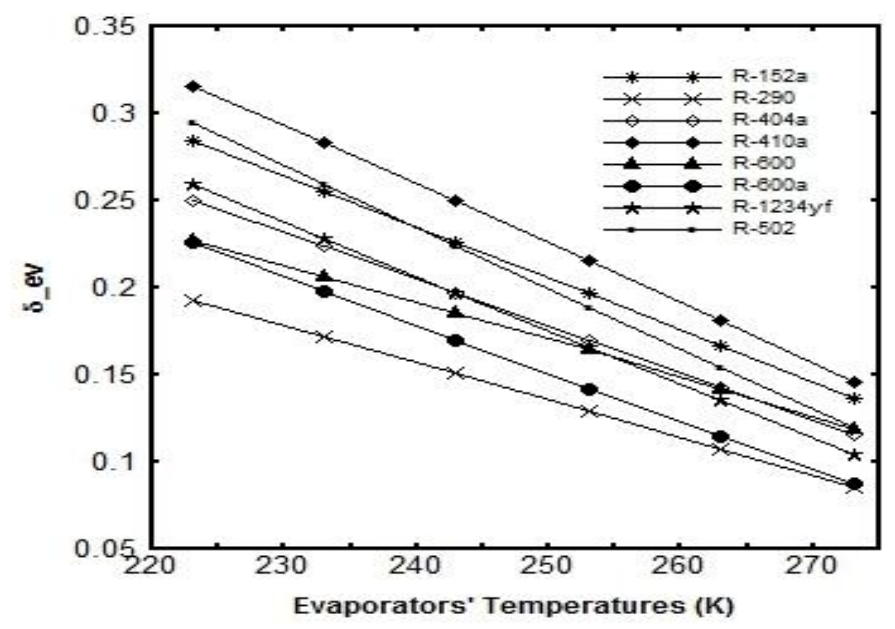

Figure 7: Comparison of efficiency defect in expansion valve $\left(\delta_{e v}\right)$ with evaporators' temperatures

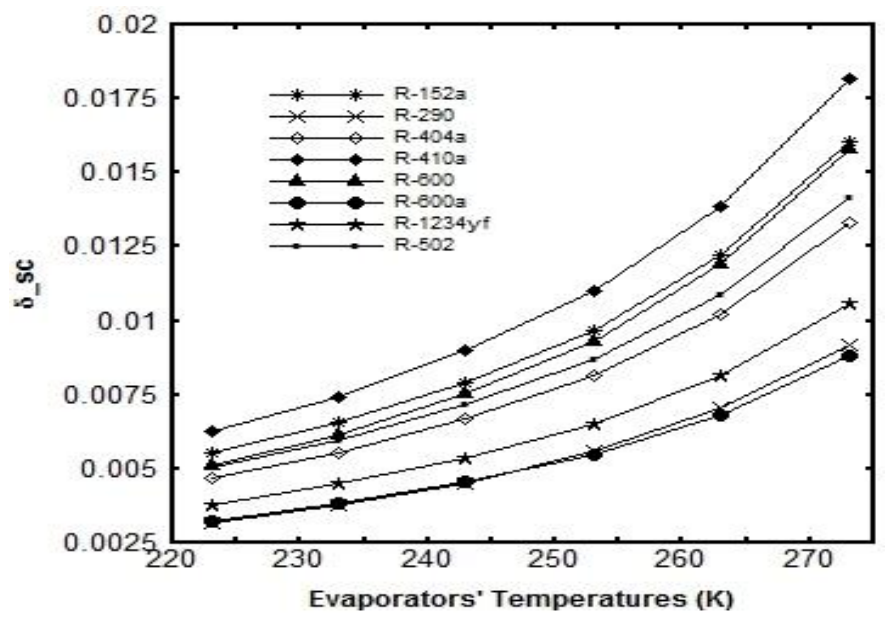

Figure 8: Comparison of efficiency defect in subcooler $\left(\delta_{s c}\right)$ with

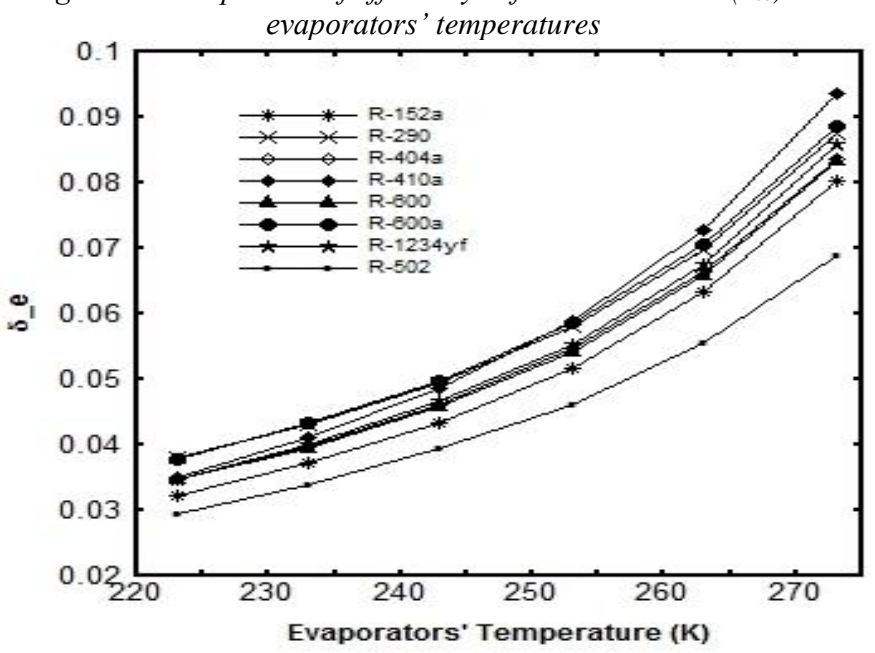

Figure 9: Comparison of efficiency defect in evaporators $\left(\delta_{e}\right)$ with evaporators' temperatures

The efficiency defect gives the idea of amount of irreversibility in a particular component. It also helps in pointing out the worst component of a system. The relationship between total of efficiency defects in different components and exergetic efficiency of the cycle is given by Eq. (20).The most efficient component of the muti-evaporators vapour compression system is subcooler in which minimum efficiency defect is observed (between $0.3 \%$ to $1.82 \%$ ).In the descending order of efficiency defects, these components can be arranged in the sequence as throttle valve, condenser, compressor, evaporators and subcooler for all the refrigerants examined. It is necessary to cite here that the input energy consumed due to irreversibility in expansion valve varies from $8 \%$ to $32 \%$ The corresponding values for compressor, condenser and evaporators vary from $19 \%$ and $24 \%$, $10 \%$ to $26 \%$ and $2 \%$ and $9 \%$, respectively. It is clear from Eq. (18) that exergetic efficiency is inversely proportional to EDR. For a fixed condenser temperature, the increase in dead state temperature causes the irreversibility (due to finite temperature difference) to decrease and hence EDR decreases and exergetic efficiency increases.Fig. 10 presents that R-404a shows maximum 
EDR among all the refrigerants corresponding to the range of dead state temperatures considered.

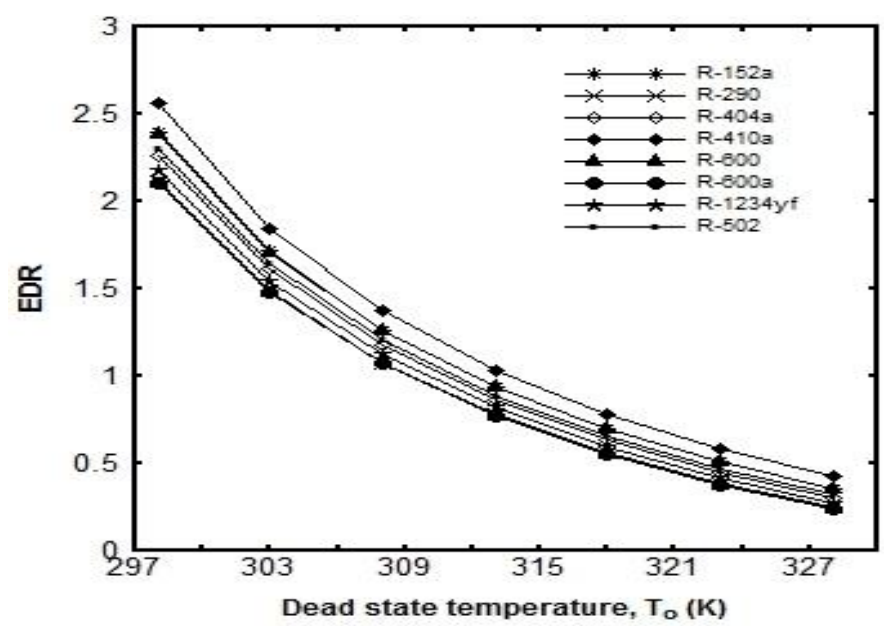

Figure 10: Variation of EDR vs dead state temperature $\left(T_{e}=273 \mathrm{~K}, T_{c}=313 \mathrm{~K}\right)$

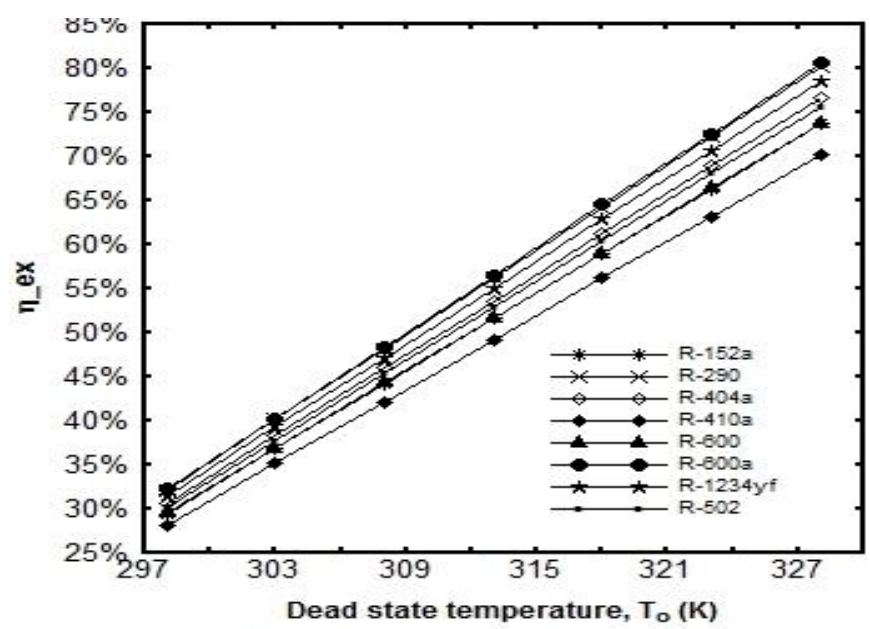

Figure 11: Variation of exergetic efficiency $\left(\eta_{e x}\right)$ vs dead state temperature

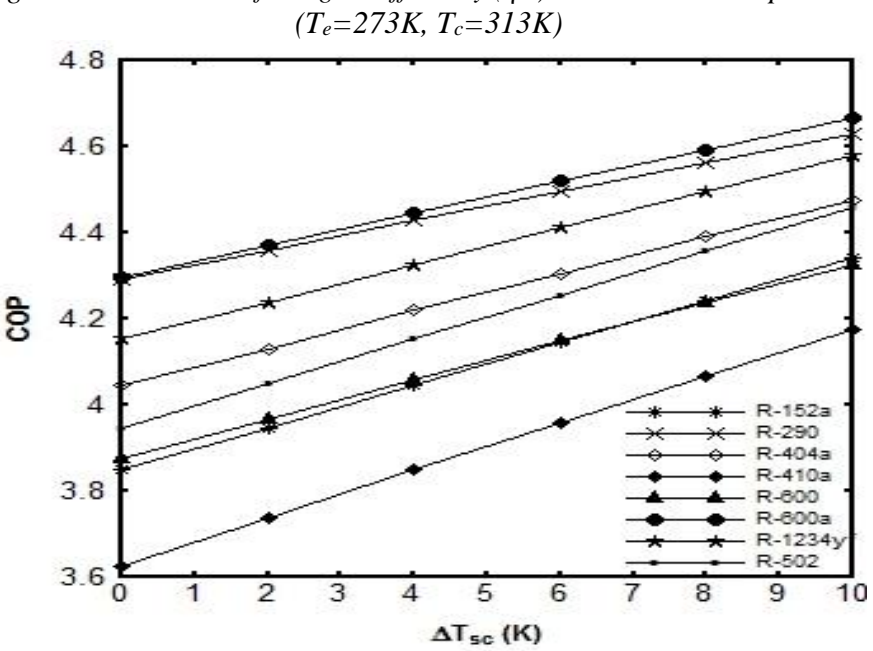

Figure 12: Effect of degree of subcooling $\left(\Delta T_{s c}\right)$ on $C O P\left(T_{e}=273 \mathrm{~K}\right.$,

$$
\left.T_{c}=313 \mathrm{~K}\right)
$$

ig 11 shows the variation of exergetic efficiency with increase of dead state temperature. Both R-152a and R-600 show the identical trends and their curves for exergetic efficiency are nearly overlapping. The exergetic efficiency for R-600 is $0.4-$ $0.5 \%$ higher than that of R-152a for the range of dead state temperature considered. Figs. 12-14 show the effect of degree of subcooling on COP, exergetic efficiency and EDR. It is evident that subcooling increases refrigeration capacity whereas there is no change in compressor work, hence COP increases. Analysis of equations through (16)-(18), makes it apparent that increase in COP decreases EDR and increases exergetic efficiency.

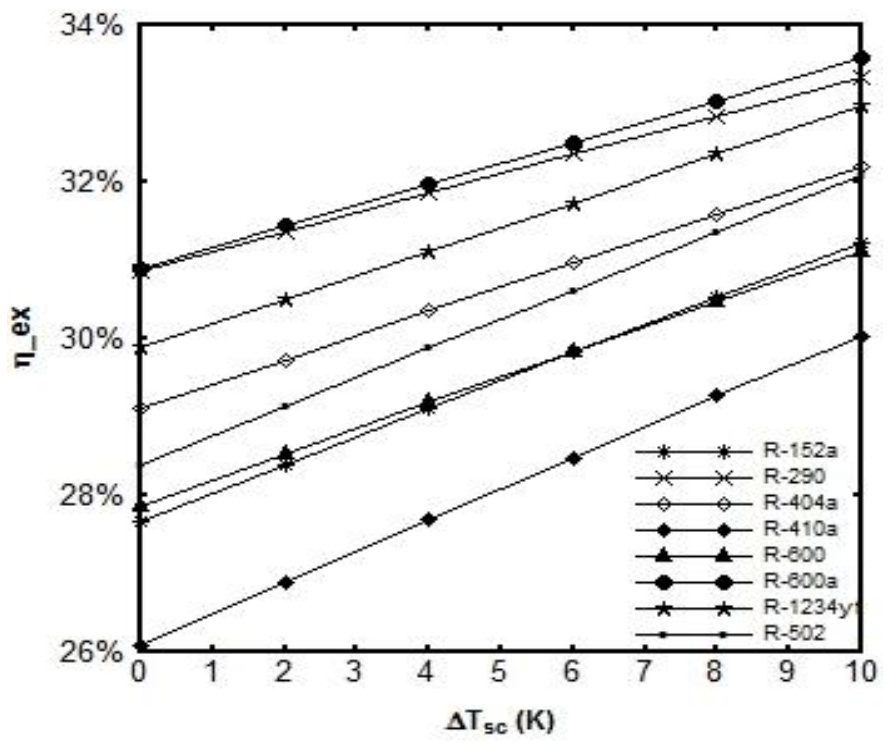

Figure 13: Effect of degree of subcooling $\left(\Delta T_{s c}\right)$ on exergetic efficiency $\left(\eta_{e x}\right)\left(T_{e}=273 K, T_{c}=313 K\right)$

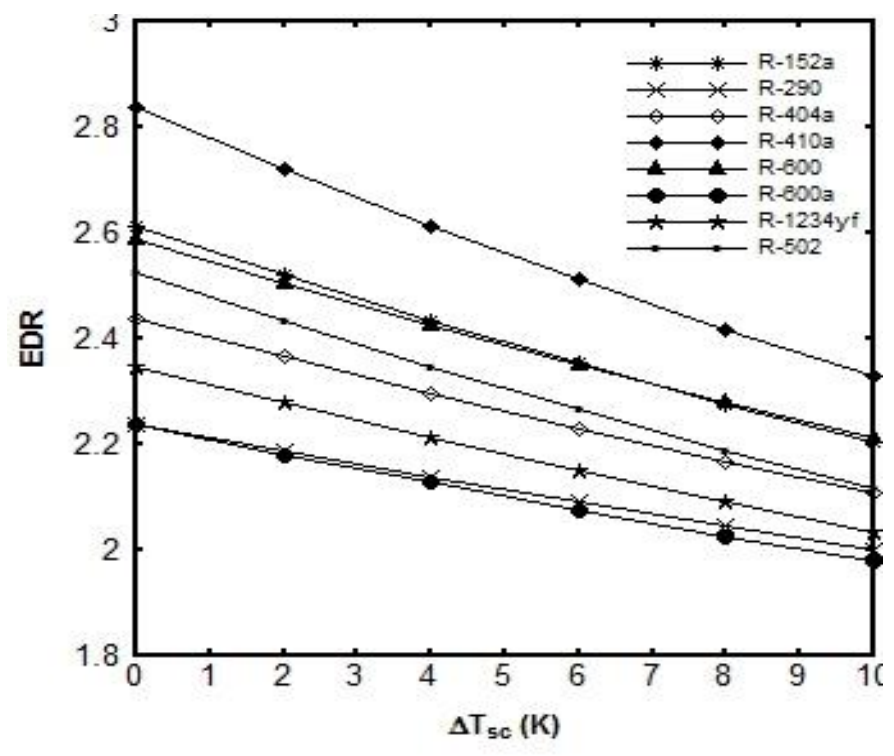

Figure 14: Effect of degree of subcooling $\left(\Delta T_{s c}\right)$ on $E D R\left(T_{e}=273 \mathrm{~K}\right.$, $\left.T_{c}=313 K\right)$ 


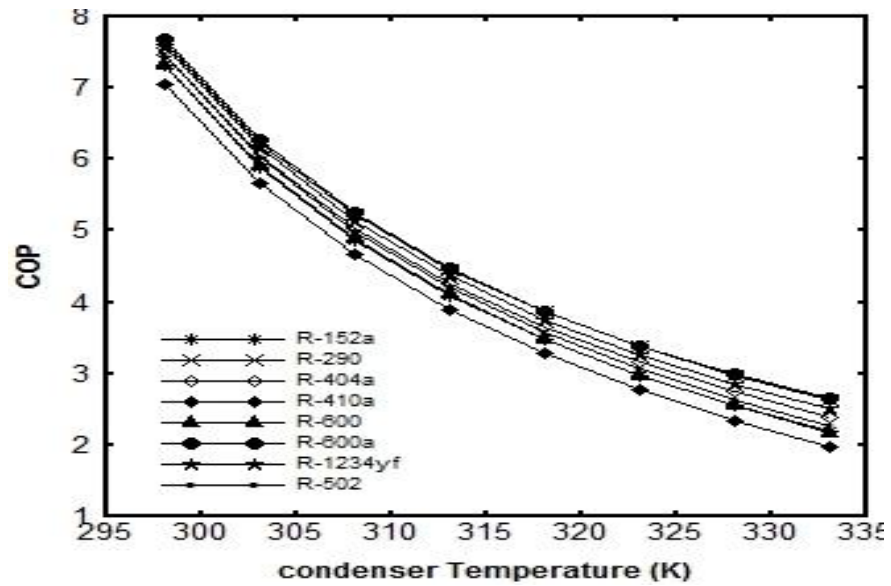

Figure 15: Variation of COP with condenser temperature $\left(\Delta T_{s c}=5 \mathrm{~K}\right.$, $\left.T_{e}=273 K\right)$

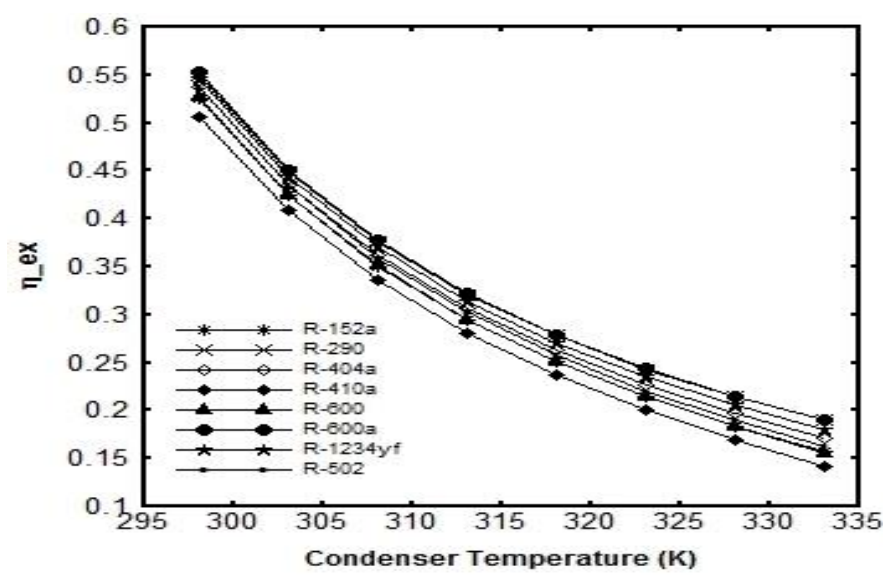

Figure 16: Variation of exergetic efficiency with condenser temperature $\left(\Delta T_{s c}=5 K, T_{e}=273 K\right)$

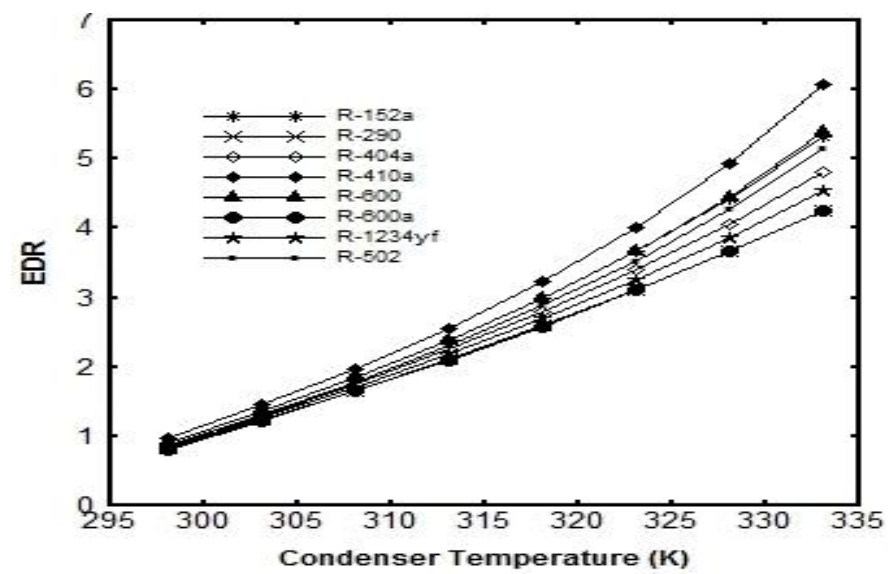

Figure 17: Variation of EDR with condenser temperature $\left(\Delta T_{s c}=5 \mathrm{~K}\right.$, $\left.T_{e}=273 K\right)$

The increase in COP is nearly $5.6 \% / \mathrm{K}$ of subcooling in case of $\mathrm{R}$ 404a.However, the corresponding increase in COP in R-152a and $\mathrm{R}-600$ is less. The rate of increase of exergetic efficiency is approximately $0.4 \% / \mathrm{K}$ for R404a.The total increase in exergetic efficiency for $10 \mathrm{~K}$ of subcooling is $3.97 \%$ for $\mathrm{R} 404 \mathrm{a}$ and $2.5 \%$ for R152a and R-600 at 313K condenser temperature. Eq. (17) demonstrates the effect of COP of the system on EDR and second law efficiency. Hence it is easy to understand why EDR increases and second law efficiency decreases

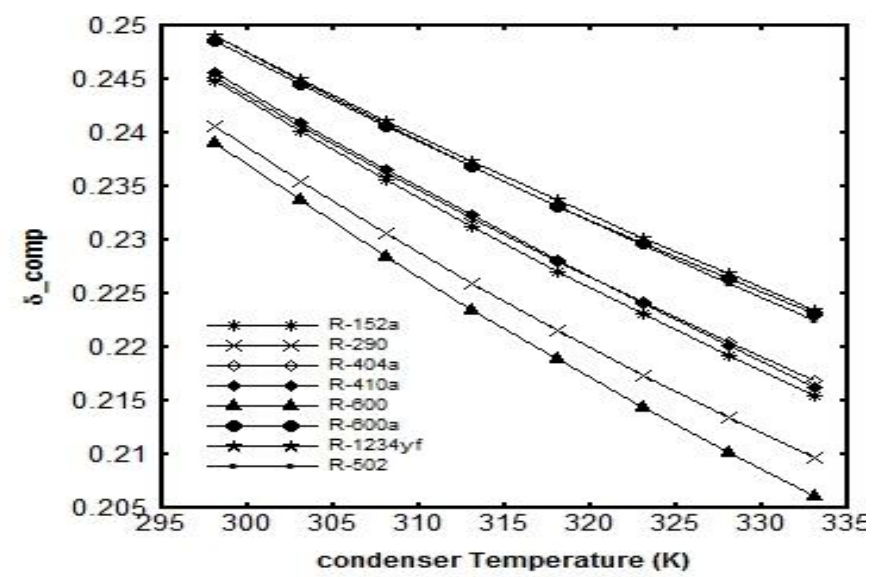

Figure 18: Variation of defect in compressor $\left(\delta_{\text {comp }}\right)$ with condenser temperature $\left(\Delta T_{s c}=5 K, T_{e}=273 K\right)$

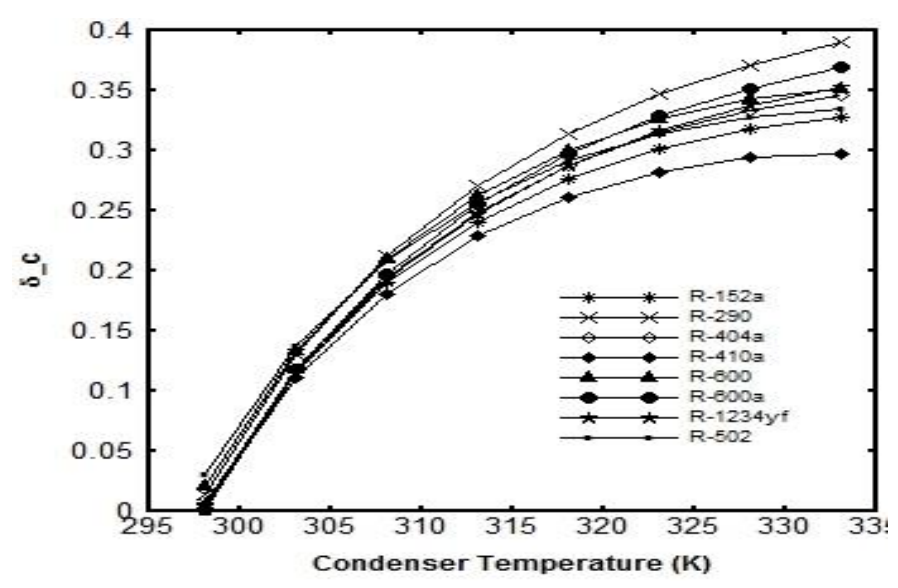

Figure 19: Variation of defect in condenser $\left(\delta_{c}\right)$ with condenser temperature $\left(\Delta T_{s c}=5 K, T_{e}=273 K\right)$

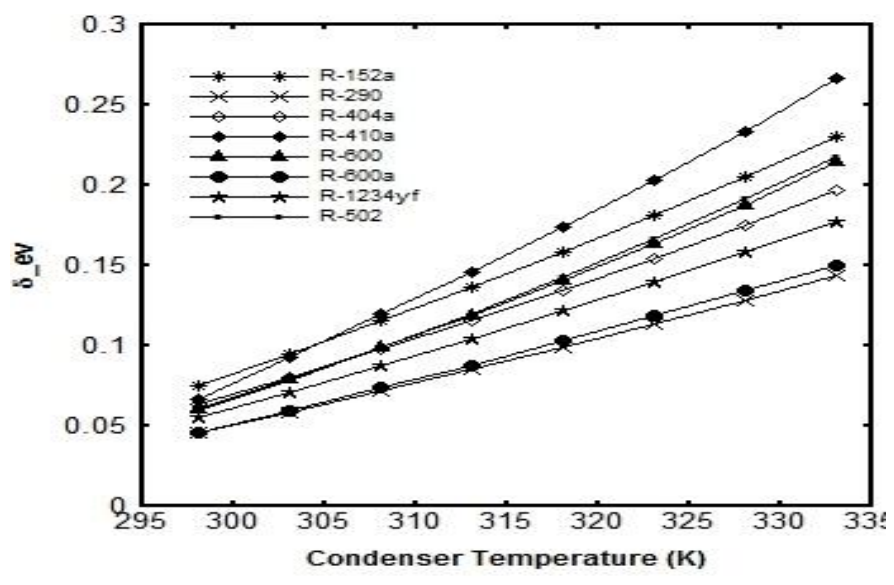

Figure 20: Variation of defect in expansion valve $\left(\delta_{e v}\right)$ with condenser temperature $\left(\Delta T_{s c}=5 K, T_{e}=273 K\right)$ 


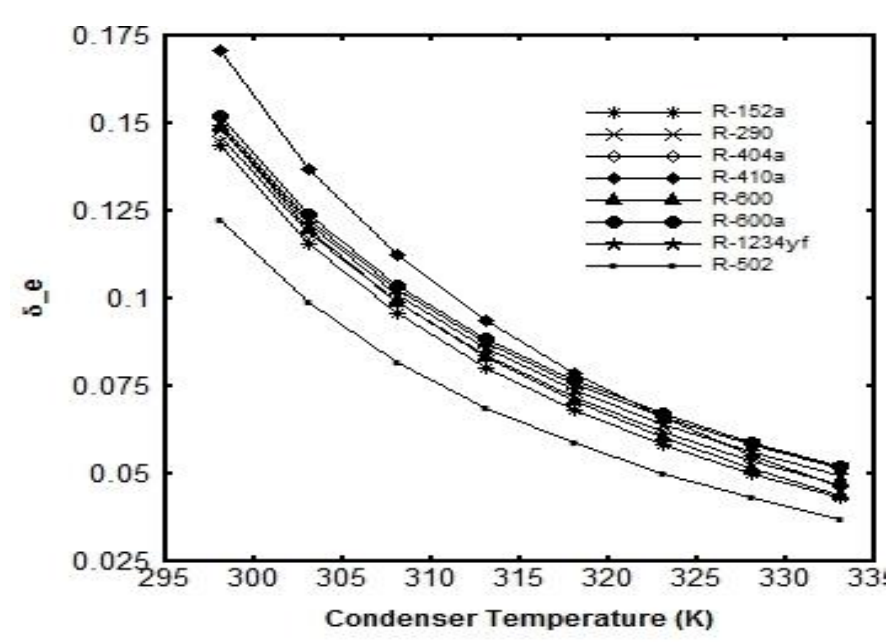

Figure 21: Variation of defect in evaporators $\left(\delta_{e}\right)$ with condenser temperature $\left(\Delta T_{s c}=5 K, T_{e}=273 K\right)$

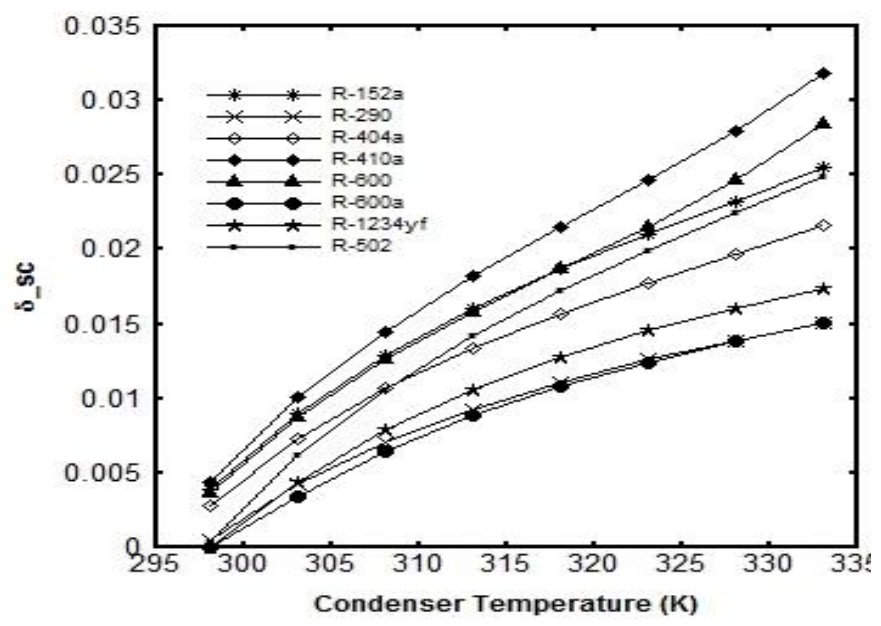

Figure 22: Variation of defect in subcooler $\left(\delta_{s c}\right)$ with condenser temperature $\left(\Delta T_{s c}=5 K, T_{e}=273 K\right)$

It is observed from Fig.15 and Fig.16 that trends of COP and exergetic efficiency are almost same for considered refrigerants, both COP and exergetic efficiency will decrease with increase in condenser temperature. Fig 17 shows that EDR increase with increase in condenser temperature at $273 \mathrm{~K}$ temperature of all evaporators with $5 \mathrm{~K}$ degree of subcooling.

The variation of efficiency defects in the compressor, condenser, expansion valve, evaporators and subcooler with condenser temperature are shown in Figs. 18-22. The efficiency defect helps in measure of amount of losses due irreversibility in a particular component. The efficiency defect in subcooler is lowest (from $0.2 \%$ to $3 \%$ ) and efficiency defect in condenser is highest $(0.5 \%$ $36.89 \%)$.The respective values for compressor, expansion valve and evaporators are upto $22 \%, 23 \%$ and $15 \%$ respectively.

\section{Conclusions}

The first law and second law analysis of an actual multievaporators vapour compression refrigeration system using ecofriendly refrigerants (R410a, R290, R600, R600a, R1234yf,
R502, R404a and R152a) have been presented in this paper. The conclusions of the present analysis are summarized below:

1. First law and second law efficiency for R152a and R600 are matching the same values. Both are better than that for R $404 \mathrm{~A}$ at $313 \mathrm{~K}$ condenser temperature and showing $12-23 \%$ higher value of COP and second law efficiency in comparison to R404a.

2. By keeping constant condenser temperature the worst component from the viewpoint of irreversibility is expansion valve followed by condenser, compressor and evaporators, respectively. The most efficient component is subcooler. The $\mathrm{R}-152 \mathrm{a}$ has lowest efficiency defects for $313 \mathrm{~K}$ condenser temperature.

3. For constant evaporator temperature subcooler is the efficient and condenser is the worst component from the viewpoint of irreversibility.

4. The increase in dead state temperature has a positive effect on exergetic efficiency and EDR, i.e. EDR decreases and exergetic efficiency increases with increase in dead state temperature. Both R-152a and R-600 show the identical trends and their curves for exergetic efficiency are nearly overlapping. The exergetic efficiency for R-600 is $0.4-0.5 \%$ higher than that of R-152a for the range of dead state temperature

\section{References}

[1] M. Padilla, R. Revellin, J. Bonjour - Exergy analysis of R413A as replacement of R12 in a domestic refrigeration system. Energy Conversion and Management 51, 2195-2201 (2010).

[2] H.O.Spauschus - HFC 134a as a substitute refrigerant for CFC 12. . Int J Refrig 11:389-92 (1988).

[3] J.U. Ahamed, R.Saidur, H.H.Masjuki - A review on exergy analysis of vapor compression refrigeration system. Renewable andSustainableEnergyReviews 15,1593-1600 (2011).

[4] R. Llopis, E. Torrella, R. Cabello, D. Sánchez -Performance evaluation of $\mathrm{R} 404 \mathrm{~A}$ and R507A refrigerant mixtures in an experimental double-stage vapour compression plant. Applied Energy 87, 1546-1553(2010).

[5] A. Arora, S.C. Kaushik - Theoretical analysis of a vapour compression refrigeration system with R502, R404A and R507A. International Journal of Refrigeration 31, 998 - 1005 (2008).

[6] V. Havelsky' - Investigation of refrigerating system with R12 refrigerant replacements. Appl Therm Eng;20:133-40 (2000).

[7] Dincer, I., 2003. Refrigeration Systems and Applications. Wiley,UK, p. 26.

[8] Lee, S.F., Sherif, S.A., 2001. Second law analysis of various double effect lithium bromide/water absorption chillers. ASHRAE Transactions AT-019-5, 664-673.

[9] Bejan, A., Tsatsaronis, G., Moran, M., 1996. Thermal Design and Optimization. John Wiley and Sons Inc., USA, pp. 143-156.

[10] Said, S.A., Ismail, B., 1994. Exergetic assessment of the coolants HCFC123, HFC134a, CFC11 and CFC12. Energy 19 (11), 1181-1186.

[11] Kotas, T.J., 1985. The Exergy Method of Thermal Plant Analysis.Butterworths, London, pp. 73-74.

[12] Klein, S.A., Alvarado, F., 2005. Engineering Equation Solver,Version 7.441. F Chart Software, Middleton, WI.

\section{Nomenclature}

COP coefficient of performance (non-dimensional)

VCR vapour compression refrigeration

CFC chlorofluorocarbon

HCFC hydrochlorofluorocarbon

$\mathrm{Q}$ rate of heat transfer $(\mathrm{kW})$

W work rate $(\mathrm{kW})$ 
$\mathrm{T}$

$\delta$

$\Delta \mathrm{T}_{\mathrm{sc}}$

$\mathrm{EP}$

EV

EP

\section{Subscript}

$\mathrm{e}$

comp

o

r temperature $(\mathrm{K})$

efficiency defect (non-dimensional)

degree of subcooling

exergy rate of product $(\mathrm{kW})$

Expansion Valve

Evaporator

evaporator

compressor

dead state

refrigerant, space to be cooled sc subcooler

$\mathrm{k} \quad$ kth component

c condenser

ev expansion valve

ex exergetic

$\mathrm{h} \quad$ specific enthalpy $(\mathrm{kJ} / \mathrm{kg})$

$\mathrm{P} \quad$ pressure $(\mathrm{kPa})$

IR irreversibility $(\mathrm{kW})$

$\mathrm{E}_{\mathrm{x}} \quad$ exergy rate of fluid $(\mathrm{kW})$

$\mathrm{m}$ mass flow rate $(\mathrm{kg} / \mathrm{s})$

s specific entropy $(\mathrm{kJ} / \mathrm{kgK})$

$\mathrm{EF}$ exergy rate of fuel $(\mathrm{kW})$

EL exergy loss rate $(\mathrm{kW})$

$\eta \quad$ efficiency (non-dimensional)

Cite this article as: R.S. Mishra, Kapil Chopra, Energy \& Exergy analysis (Thermodynamic analysis) of a multi-evaporators vapour compression refrigeration system using ecofriendly refrigerants (R410a, R290, R600, R600a, R1234yf, R502, R404a and R152a), International Journal of Research in Engineering and Innovation Vol-3, Issue-5 (2019), 343-351. 